\title{
SLOWING OF THE AXONAL TRANSPORT OF NEUROFILAMENT PROTEINS DURING DEVELOPMENT ${ }^{1}$
}

\author{
PAUL N. HOFFMAN, ${ }^{*, 2}$ RAYMOND J. LASEK, $\ddagger$ JOHN W. GRIFFIN,§ AND DONALD L. PRICE\| \\ ${ }^{*}$ Neuropathology Laboratory and Department of Ophthalmology, The Johns Hopkins University School of Medicine, \\ Baltimore, Maryland 21205; $\ddagger$ Department of Anatomy, Case Western Reserve University, Cleveland, Ohio 44106; \$Neuromuscular \\ Laboratory, Department of Neurology, and $\|$ Neuropathology Laboratory, Departments of Pathology and Neurology, The Johns \\ Hopkins University School of Medicine, Baltimore, Maryland 21205
}

Received November 22, 1982; Revised March 9, 1983; Accepted March 10, 1983

\begin{abstract}
We examined age-dependent changes in neurofilament transport in motor axons of the rat sciatic nerve. SDS-PAGE and gel fluorography confirmed that the distribution of labeled neurofilament triplet protein coincides with the major slow component $a(\mathrm{SCa})$ wave in these neurons. The velocity of neurofilament transport was calculated on the basis of the location of the 50th percentile of radioactivity in this wave 33 days after motor neurons were labeled by the intraspinal administration of $\left[{ }^{3} \mathrm{H}\right]$ leucine and $\left[{ }^{3} \mathrm{H}\right]$ lysine. Overall, the velocity fell from $1.95 \mathrm{~mm} /$ day at 3 weeks of age to 1.12 $\mathrm{mm} /$ day at 20 weeks. Between 3 and 10 weeks, it fell at a 6 -fold higher rate $(0.096 \mathrm{~mm} /$ day/week $)$ than between 10 and 20 weeks $(0.016 \mathrm{~mm} /$ day/week $)$. We also found a marked change in the shapc of the slow component wave during development. It appeared to consist of several overlapping peaks moving at slightly different velocities in animals 10 weeks of age or less as compared to a single slower moving peak at 20 weeks. We propose that the velocity of slow axonal transport reflects the level of maturation of the neuron, and that the presence of several overlapping peaks of transported radioactivity in the sciatic nerve of younger animals reflects the presence of several populations of motor axons at different stages of development. We also discuss the relationship between changes in the velocity of neurofilament transport and alterations in the composition of the cytoskeleton that occur as the axon grows in caliber during postnatal development.
\end{abstract}

A major feature of the postnatal development of myelinated axons is their radial growth, i.e., growth in caliber, which underlies increased conduction velocity in developing neurons (Swallow and Griffiths, 1977; Sims and Redding, 1980). Morphometric analyses disclose that neurofilaments of the axonal cytoskeleton play an important role in this process. As the cross-sectional area of the axon increases, there is a proportional rise in the number of neurofilaments (Friede and Samorajski, 1970; Weiss and Mayr, 1971; Berthold, 1978).

The protein subunits of neurofilaments, the neurofilament triplet proteins $\left(M_{\mathrm{r}}=200,145\right.$, and 68 kilodal-

\footnotetext{
${ }^{1}$ P. N. H. is a John A. and George L. Hartford Foundation Fellow and an Alfred P. Sloan Foundation Research Fellow. This work was supported by Public Health Service Grants EY 03791, NS 10580, and NS 15721. J. W. G. is the recipient of a United States Public Health Service Research Career Development Award (National Institutes of Health NS 00450). The authors thank Mrs. Carla Jordon and Mr. David Andrews for their careful assistance during preparation of the manuscript.

${ }^{2}$ To whom correspondence should be addressed.
}

tons $(\mathrm{kd})$, respectively), are synthesized in the neuron cell body and, along with actin and tubulin, are slowly transported in the axon at velocities of several millimeters per day (Hoffman and Lasek, 1975). Several previous studies have shown that the velocity of slow axonal transport is faster in young animals than in adults (Droz, 1965; Lasek, 1970; Hendrickson and Cowan, 1971; Komiya, 1980). Thus, radial growth, which involves an increase in neurofilament number, is correlated with a reduction in the velocity of neurofilament transport. The additional observation that radial growth occurs at a faster rate in young animals than in adults (Skoglund and Romero, 1965; Nystrom, 1968; Braund et al., 1982) has prompted us to examine this relationship in greater detail in the sciatic motor axons of rats ranging from 3 to 20 weeks of age.

\section{Materials and Methods}

\section{Labeling axonal proteins in lumbar motor neurons}

The sciatic motor neurons of male Wistar rats were labeled at $3,5,7,10$, and 20 weeks of age. The average 
weights of these animals were $50,135,215,400$, and 550 gm, respectively.

Microliter quantities of labeled amino acids were injected into the lumbar spinal cord using our published method (Hoffman and Lasek, 1975). For radiometric studies, motor neurons were labeled with a mixture of $\mathrm{L}^{-}$ $4,5-\left[{ }^{3} \mathrm{H}\right](\mathrm{N})$ leucine $(30$ to $50 \mathrm{Ci} / \mathrm{mmol})$ and $\mathrm{L}-4,5-\left[{ }^{3} \mathrm{H}\right]$ (N)lysine (20 to $40 \mathrm{Ci} / \mathrm{mmol}$ ), each at a final concentration of $5 \mathrm{mCi} / \mathrm{ml}$ (New England Nuclear Corp., Boston, MA). For gel fluorography, proteins were labeled with L$\left[{ }^{35}\right.$ S $]$ methionine $(1200 \mathrm{Ci} / \mathrm{mmol}$ ) (Amersham Corp., Arlington Heights, IL) at a final concentration of $80 \mathrm{mCi} /$ ml. Animals were killed at $10,20,33,60$, and 85 days after labeling.

\section{Distribution of labeled protein in rat sciatic nerve}

After rats were anesthetized and killed by perfusion with formalin, the sciatic nerves were removed and divided into 3-mm segments. Segments were dissolved in Soluene (Packard Instruments, Downers Grove, IL), and the levels of radioactivity were measured using liquid scintillation spectroscopy (Hoffman and Lasek, 1975).

\section{Analysis of labeled proteins using SDS-PAGE fluorography}

The sciatic nerve and roots were quickly removed from animals killed by decapitation and were either processed immediately or stored at $-60^{\circ} \mathrm{C}$ for analysis at a later time. Consecutive $3-\mathrm{mm}$ segments of the nerve were homogenized in $400 \mu \mathrm{l}$ of $1 \% \mathrm{SDS}, 8 \mathrm{M}$ urea, and $5 \% \beta$ mercaptoethanol (SUB). Homogenates were incubated at $100^{\circ} \mathrm{C}$ for $4 \mathrm{~min}$ and then clarified by centrifugation at $8,000 \times g$ for 5 min using a Microfuge B (Beckman Instruments, Inc., Palo Alto, CA). This latter step represents a modification of the method of Hoffman and Lasek (1975). Aliquots were removed for liquid scintillation spectroscopy $(10 \mu \mathrm{l})$ and for analysis using SDSPAGE $(200 \mu \mathrm{l})$ on gradient slab gels $(1 \times 100 \times 120 \mathrm{~mm}$, 5 to $17.5 \%$ acrylamide) in a discontinuous Tris buffer system (Hoffman and Lasek, 1975). Gels were stained in Coomassie blue, destained in methanol, and impregnated with scintillation fluor by immersion in Enhance (New England Nuclear). They were then placed between two sheets of dialysis membrane, which had been hydrated previously in $10 \%$ glycerol, and were dried using a commercial apparatus. Fluorographs were prepared according to the method of Laskey and Mills (1975) using Kodak RP x-ray film. Fluorographs were developed after exposure for several weeks at $-60^{\circ} \mathrm{C}$.

The molecular weights of labeled proteins were estimated by comparing their electrophoretic mobilities with those of protein standards: rat muscle myosin $\left(M_{\mathrm{r}}=200\right.$ $\mathrm{kd})$, rabbit muscle phosphorylase (94 kd), BSA $(68 \mathrm{kd})$, pig brain tubulin $(55 \mathrm{kd})$, and rat muscle actin $(43 \mathrm{kd})$.

\section{Results}

\section{Decline in velocity of the slow component during development}

The distribution of radioactive protein in the sciatic nerve of a 3 -week-old animal as examined radiometrically 10 days after labeling motor neurons with $\left[{ }^{35} \mathrm{~S}\right]$ methionine is shown in Figure 1. Note that only $66 \mathrm{~mm}$ of nerve were available for analysis in these relatively young animals at that time ( 1 month old at the time of sacrifice). This analysis revealed the presence of a major wave of radioactivity in the nerve located 18 to $45 \mathrm{~mm}$ from the spinal cord (between segments $A$ and $B$ ). The composition of labeled polypeptides in this nerve was examined using SDS-PAGE and gel fluorography (Fig. 2 ). This analysis disclosed that the distribution of neurofilament triplet proteins $\left(M_{\mathrm{r}}=200,145\right.$, and $\left.68 \mathrm{kd}\right)$ coincided with this major wave (Fig. 2). Tubulin (55 kd), actin $(43 \mathrm{kd})$, and a heterogeneous group of proteins representative of slow component $b(\mathrm{SCb})$, many with molecular weights ranging from 70 to $170 \mathrm{kd}$, were present in this wave and also in more distal regions of the nerve. Similar analyses disclosed that the presence of these latter proteins extended into distal portions of the nerve as early as 5 days after labeling (data not shown). Since the distribution of neurofilament triplet proteins coincided with the major slow component wave in these neurons, the velocity of neurofilament transport was inferred from the location of this wave as disclosed by radiometric analysis.

Differences in the position of the slow component wave in sciatic nerves of 3-, 5-, 7-, 10-, and 20-week-old rats 33 days after labeling motor neurons with $\left[{ }^{3} \mathrm{H}\right]$ leucine and $\left[{ }^{3} \mathrm{H}\right]$ lysine are illustrated in Figure 3. In these profiles, the wave is located farther distally in younger animals. In 3-week-old animals, only the trailing edge of the slow component wave, located 60 to $75 \mathrm{~mm}$ from the spinal cord, was seen 33 days after labeling. By this time, labeled proteins traveling in the leading portion of this wave had already reached the terminal branches of motor

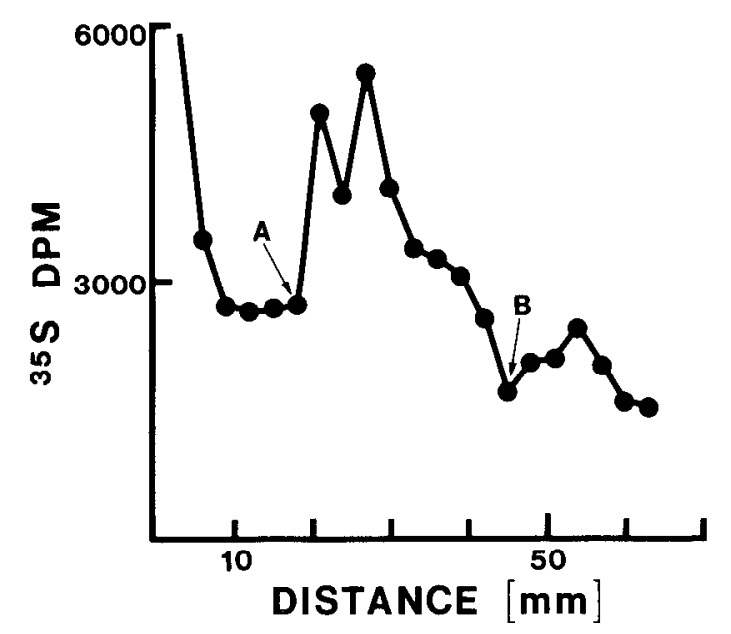

Figure 1. The distribution of radioactive protein in the sciatic nerve of a 3 -week-old rat is examined 10 days after motor neurons were labeled by the intraspinal administration of $\left[{ }^{35} \mathrm{~S}\right]$ methionine. This nerve was divided into $3-\mathrm{mm}$ segments, which were homogenized in $400 \mu \mathrm{l}$ of SUB (see "Materials and Methods"). The level of radioactivity in $10-\mu \mathrm{l}$ aliquots of these homogenates was measured using liquid scintillation spectroscopy and was plotted as a function of distance from the spinal cord. Aliquots $(200 \mu \mathrm{l})$ were analyzed on a gradient slab gel using SDS-PAGE (Fig. 2). A major wave of radioactivity is located 18 to $45 \mathrm{~mm}$ from the spinal cord, i.e., between segments $A$ and $B$. 


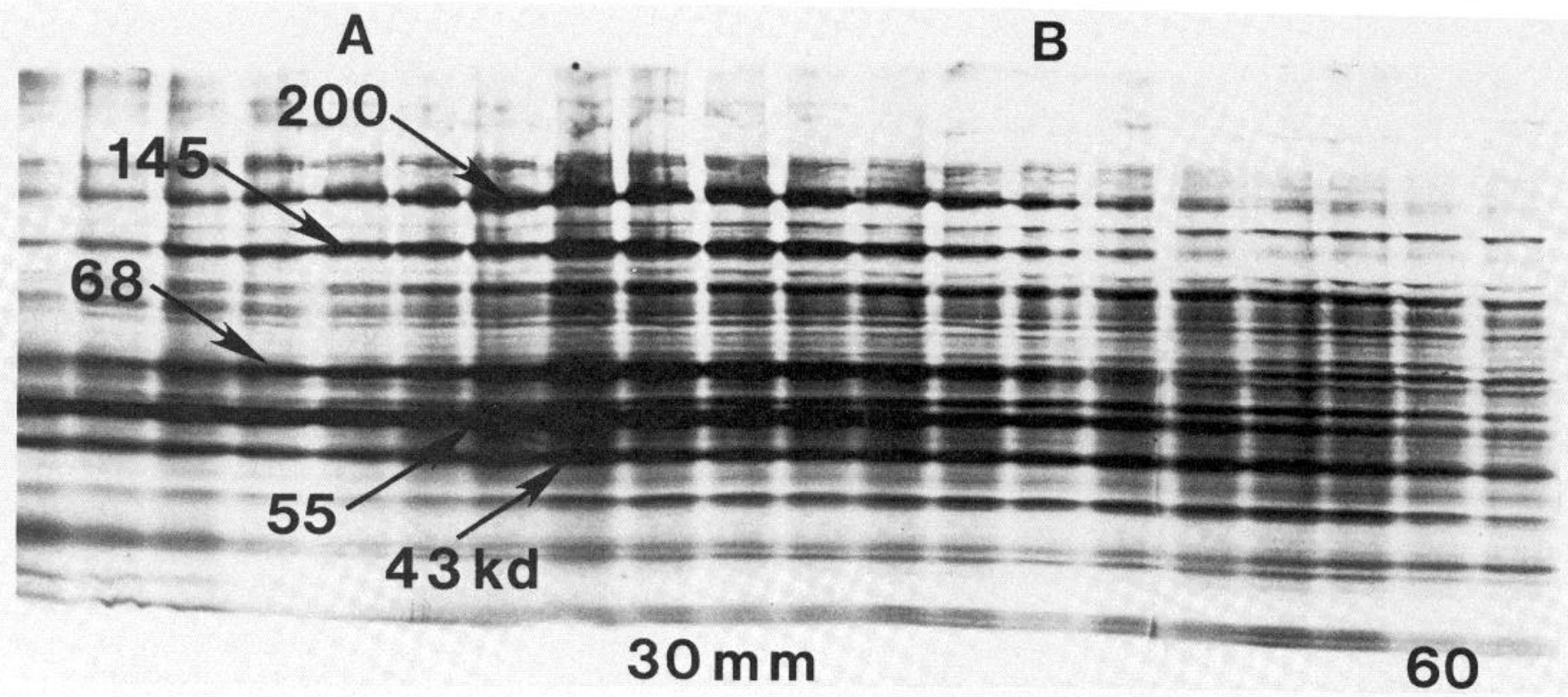

Figure 2. This fluorograph illustrates the distribution of labeled polypeptides in the sciatic nerve of a 3 -week-old animal at 10 days after labeling motor neurons with $\left[{ }^{35} \mathrm{~S}\right]$ methionine. The distribution of radioactivity in this nerve is examined in Figure 1. Aliquots $(200 \mu \mathrm{l})$ of nerve homogenates were analyzed on a gradient slab gel (5 to $17.5 \%$ acrylamide) using SDS-PAGE. Vertical gel slots contain labeled proteins from consecutive $3-\mathrm{mm}$ nerve segments. The distance of these segments from the spinal cord is indicated at the bottom of this gel. The positions of the labeled neurofilament triplet proteins $\left(M_{\mathrm{r}}=200\right.$, 145, and $\left.68 \mathrm{kd}\right)$, tubulin $(55 \mathrm{kd})$, and actin $(43 \mathrm{kd})$, and also the gel slots corresponding to nerve segments $A$ and $B$ in Figure 1 , are shown. This fluorograph was exposed for 2 weeks.

axons innervating muscles in the relatively short legs of these animals. This was reflected in the sharp decline in radioactivity at distances of 75 to $87 \mathrm{~mm}$ in these nerves (Fig. 3).

In order to measure the velocity of the slow component, the cumulative percentile of radioactivity in these profiles was expressed as a function of distance along the nerve, and the location of the 50th percentile of radioactivity was taken as a measure of distance the wave had traveled. In order for this to reflect accurately the location of the slow component, it was necessary to select postlabeling intervals at which the entire wave was located in the portion of the nerve used for this analysis. For this reason, nerves were analyzed 33 days after labeling for all ages except 3 weeks; in this latter group they were analyzed at 20 days (Fig. 4).

Previous studies have demonstrated that the proximal $10 \mathrm{~mm}$ of the rat sciatic nerve contain high levels of radioactivity resulting from the direct diffusion of labeled precursor from the injection site in the spinal cord (Lasek, 1968). This is illustrated in Figures 1 and 3 , where the first three segments $(9 \mathrm{~mm})$ contained elevated levels of radioactivity. Therefore, this region of the nerve was excluded from our analysis.

In Figure $4 A$, the cumulative percentile of radioactivity in the slow component wave 33 days after labeling was plotted as a function of distance along the nerve for 5-, 7-, 10-, and 20-week-old animals. This analysis was also carried out 20 days after labeling for the 3- and 10-weekold animals (Fig. 4B). These sigmoidal-shaped profiles were located more distally in younger animals (Fig. $4, A$ and $B$ ). The mean locations of the 50 th percentiles 33 days after labeling, and the velocities corresponding to these distances, are listed in Table I. The mean locations of the 50th percentile for neighboring age groups were found to differ with $p<0.05$ using the two-sample Student's $t$ test. In 3-week-old animals, the expected location of the 50 th percentile at 33 days was calculated on the basis of the relative positions of the 50th percentiles in 3 - and 10 -week-old animals 20 days after labeling (46.6 \pm 0.9 and $30.6 \pm 2.5 \mathrm{~mm}$, respectively). Thus, 33 days after labeling, we expect the 50 th percentile in 3 week-old animals to be located at a distance $(64.3 \mathrm{~mm})$ which is 1.52 times greater than in 10 -week-old animals at that time $(42.2 \pm 0.7 \mathrm{~mm})$ (Table I).

The velocities of the 50th percentiles of radioactivity (Table I) were plotted as a function of age in Figure 5. Regression analysis revealed that velocity declined linearly between 3 and 10 weeks of age (correlation coefficient, 0.98) at a rate of $0.096 \mathrm{~mm} /$ day/week. This was 6fold greater than the rate at which it fell in the interval between 10 and 20 weeks $(0.016 \mathrm{~mm} /$ day/week).

\section{Changes in the shape of the slow component wave during development}

In animals 10 weeks old or less, the slow component was composed of several distinct overlapping peaks (Fig. 3 ). These peaks appeared to be moving at slightly different velocities, since they became individually more apparent and the width of the entire wave increased as it traveled distally in the nerve. This is illustrated in Figure 6 , where the movement of this wave was examined in 10 week-old animals at 20,33,60, and 85 days after labeling. By 33 days, three distinct peaks had arisen from the single one present at 20 days. These peaks became increasingly more distinct at 60 and 85 days. The width of 


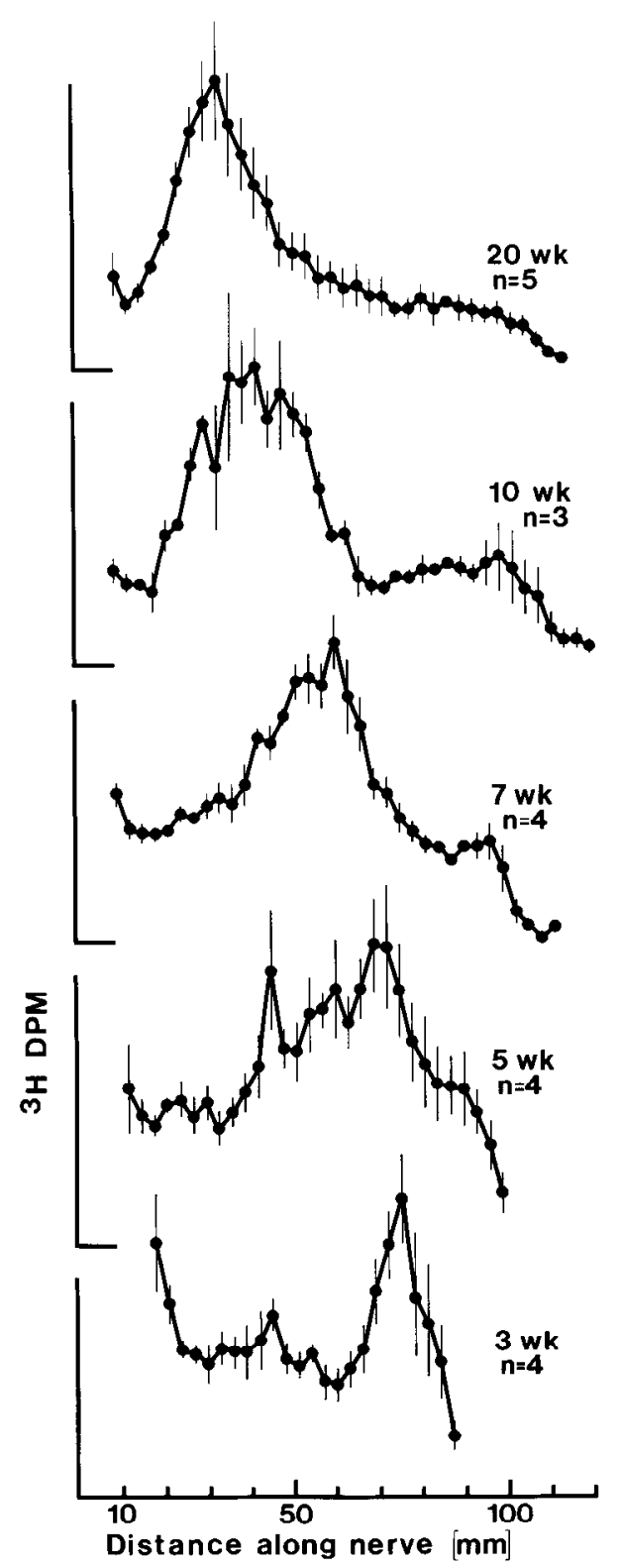

Figure 3. Slow axonal transport is compared in animals 3,5 , 7,10 , and 20 weeks of age at 33 days after labeling motor neurons with $\left[{ }^{3} \mathrm{H}\right]$ leucine and $\left[{ }^{3} \mathrm{H}\right]$ lysine. These sciatic nerves were divided into $3-\mathrm{mm}$ segments, and the level of radioactivity in each segment was determined using liquid scintillation spectroscopy. The mean levels of radioactivity are plotted as a function of distance from the spinal cord, with " $n$ " animals in each group. The standard errors of these values are indicated by vertical bars. These profiles are normalized to facilitate their comparison. The highest point in each profile represents: 3,044 $\mathrm{dpm}$ at 3 weeks of age; $2,062 \mathrm{dpm}$ at 5 weeks; 2,579 at 7 weeks; 8,814 at 10 weeks; and $20,053 \mathrm{dpm}$ at 20 weeks.

the slow component wave in 10 -week-old animals was plotted as a function of its location at each of these postlabeling intervals in Figure 7. This width was measured by a segment intersecting the leading and trailing edges of the wave at a level equal to two-thirds of its total height (broken horizontal lines, Fig. 6). The location of the wave was measured at the midpoint of this segment (indicated by arrows in Fig. 6). The width of the slow component wave was directly proportional to its distance from the spinal cord in these animals (Fig. 7). This is consistent with the suggestion that the wave comprised several peaks moving at different velocities.

These multiple peaks, which are characteristic of the slow component in animals 10 weeks old or less, were not found in the nerves of 20 -week-old animals. Since the lack of these peaks may reflect the relatively short distance the wave has traveled in these animals 33 days after labeling, e.g., as in the case of 10-week-old animals 20 days after labeling (Fig. 6), the shape of the slow

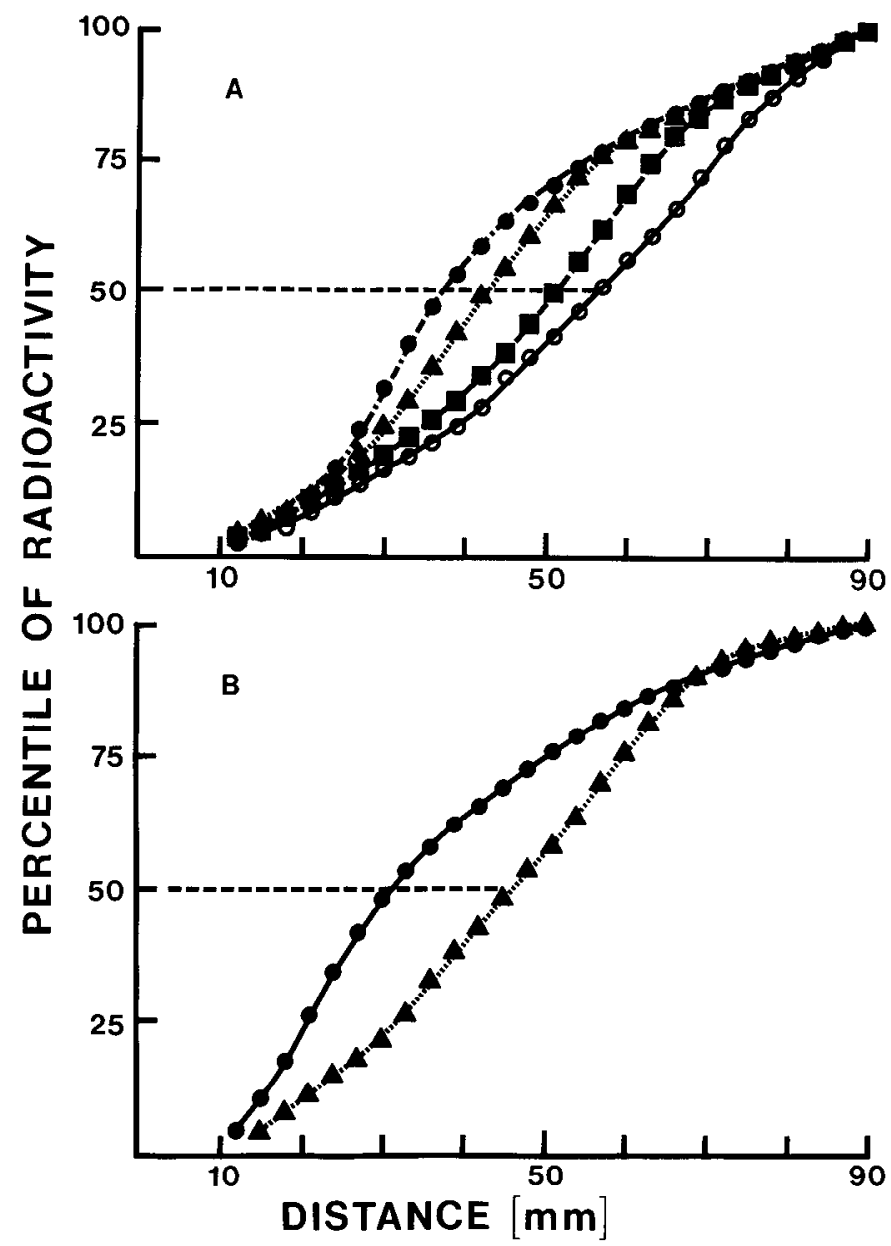

Figure 4. A, Differences in the location of the slow component wave in 5-week $(\mathrm{O} \longrightarrow \mathrm{O}$ ), 7-week ( $\square$-- $\mathbf{-}$ ), 10-week $(\boldsymbol{\Delta} \ldots \boldsymbol{\Delta} \ldots \boldsymbol{\Delta})$, and 20 -week-old $(\boldsymbol{0 . . . .})$ animals are illustrated 33 days after labeling motor neurons with $\left[{ }^{3} \mathrm{H}\right]$ leucine and $\left[{ }^{3} \mathrm{H}\right]$ lysine. The cumulative percentile of radioactivity in the sciatic nerve is plotted as a function of distance from the spinal cord. Each data point represents the means of four values at 5,7 , and 10 weeks and five values at 20 weeks. The location of the 50th percentile of radioactivity, indicated by a broken horizontal line, is used as a measure of distance the wave has traveled in these nerves (Table I). These data are presented in a different form in Figure 3 . $B$, The location of the slow component wave in 3 -week $(\boldsymbol{A} \ldots \boldsymbol{\Delta} \ldots \mathbf{\Delta})$ and 10 -week-old animals (-) is compared 20 days after labeling motor neurons with $\left[{ }^{3} \mathrm{H}\right]$ leucine and $\left[{ }^{3} \mathrm{H}\right]$ lysine. Each data point represents the mean of three values at 3 weeks and four values at 10 weeks. The 50 th percentile of radioactivity is located 45.9 $\mathrm{mm}$ from the spinal cord in 3 -week-old animals and $30.9 \mathrm{~mm}$ in 10 -week-old animals. The data for the 10 -week-old animals are plotted in a different form in Figure 6 (20-day profile). 
TABLE I

Age-related changes in the velocity of neurofilament transport

\begin{tabular}{ccc}
\hline Age & $\begin{array}{c}\text { Location of 50th Percentile } \\
\text { (Distance from Spinal Cord) }^{\circ}\end{array}$ & Averge Velocity \\
\hline weeks & $m m \pm S E M$ & $m m / d a y$ \\
3 & $64.3^{b}$ & 1.95 \\
5 & $56.6 \pm 1.2$ & 1.71 \\
7 & $49.1 \pm 2.5$ & 1.49 \\
10 & $42.2 \pm 0.7$ & 1.28 \\
20 & $36.9 \pm 1.1$ & 1.12 \\
\hline
\end{tabular}

${ }^{a}$ Mean location of the 50 th percentile of radioactivity in the slow component 33 days after labeling sciatic motor neurons with $\left[{ }^{3} \mathrm{H}\right]$ leucine and $\left[{ }^{3} \mathrm{H}\right]$ lysine ( $n=4$ at all ages except 20 weeks, where $n=$ $5)$.

${ }^{b}$ The location in 3-week-old animals at 33 days was calculated on the basis of the relative positions of the 50th percentile at 20 days after labeling in 3 - and 10-week-old animals (see the text).

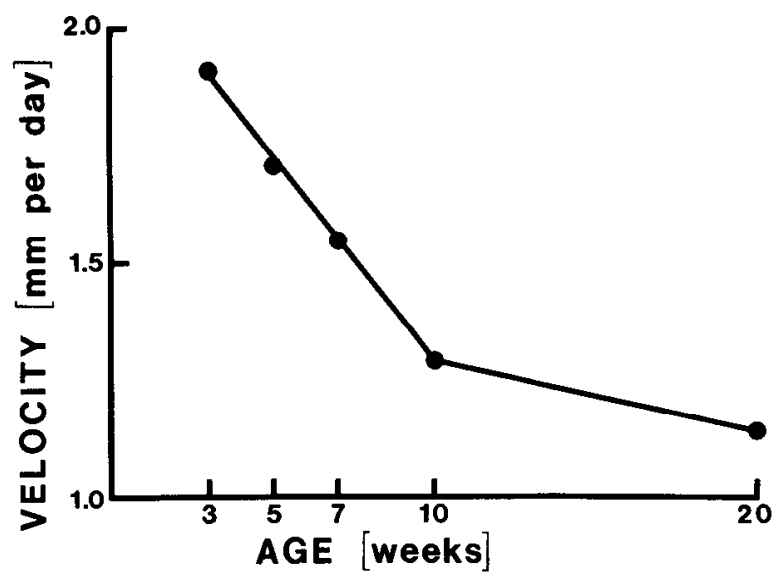

Figure 5. 'The velocity of the slow component in animals of different ages is plotted as a function of age. These velocities were calculated on the basis of the locations of the 50th percentile of radioactivity 33 days after labeling (Table I).

component wave was also examined in 20 -week-old animals 60 days after labeling (Fig. 8). This postlabeling interval was selected because the location of the wave in these animals was comparable to that in 10 -week-old animals 33 days after labeling, when it consisted of several overlapping peaks. (The 50th percentiles of radioactivity in 20-week-old animals at 60 days and in 10week-olds at 33 days were located $43.1 \pm 2.7$ and $42.2 \pm$ $0.7 \mathrm{~mm}$ from the spinal cord, respectively.) Sixty days after labeling, the wave in 20 -week-old animals consisted of a single major peak located 21 to $48 \mathrm{~mm}$ from the spinal cord and a downward sloping front of radioactivity extending approximately 48 to $120 \mathrm{~mm}$ (Fig. 8). This latter portion of the wave coincided with the location of the slow component in 10 -week-old animals at this time (Fig. 8).

\section{Discussion}

\section{Changes in velocity of neurofilament transport during development}

The neurofilament triplet proteins are transported, along with actin and tubulin, in the principal slow component wave (Hoffman and Lasek, 1975) which corresponds to the SCa component of slow axonal transport
(Lasek and Hoffman, 1976). In contrast to the neurofilament triplet proteins, which are confined exclusively to $\mathrm{SCa}$, tubulin and actin are also present in $\mathrm{SCb}$ in sciatic motor axons (Hoffman and Lasek, 1980; McQuarrie et al., 1980). SCb, which moves 3 to 4 times faster than $\mathrm{SCa}$, contains substantially less total radioactivity than $\mathrm{SCa}$ in these labeled neurons. Thus, the behavior of the principal slow component wave in these neurons most closely reflects the transport of neurofilament triplet protein. In fact, since essentially all of the neurofilament triplet protein in the axon appears to be polymerized (Morris and Lasek, 1982), this wave probably reflects the movement of neurofilaments in the axon.

Our results demonstrate the the velocity of the slow component wave declined from $1.95 \mathrm{~mm} /$ day at 3 weeks of age to $1.12 \mathrm{~mm} /$ day at 20 weeks (Table I and Fig. 5). The velocity fell at a 6 -fold greater rate $(0.096 \mathrm{~mm} /$ day/ week) between 3 and 10 weeks than between 10 and 20 weeks of age $(0.016 \mathrm{~mm} /$ day/week $)$. A number of pre-

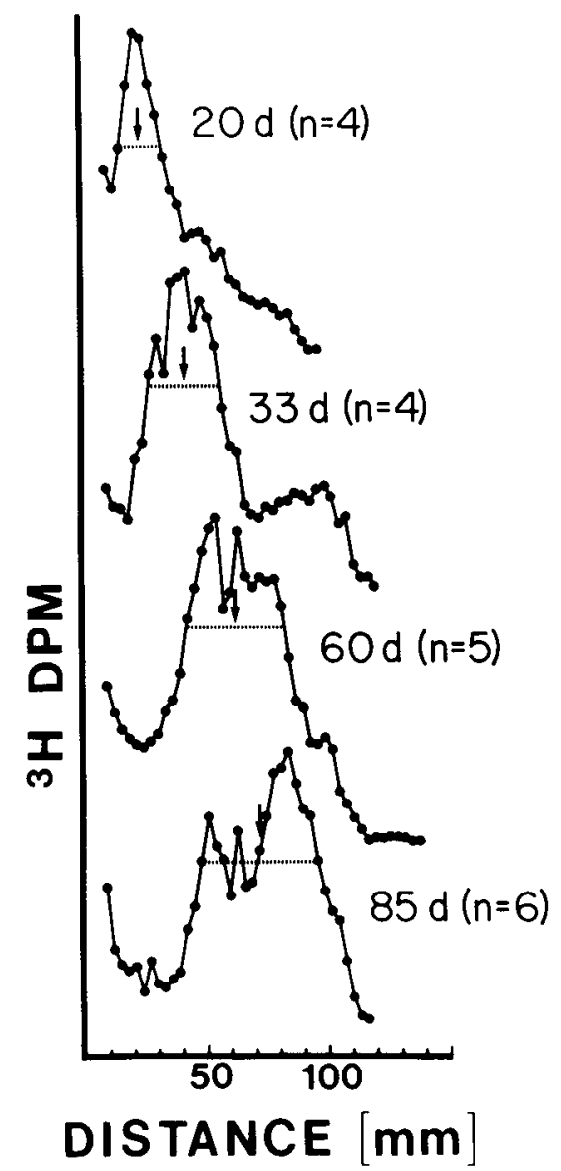

Figure 6. The presence of overlapping peaks in the slow component is demonstrated in the nerves of 10 -week-old animals at $20,33,60$, and 85 days after labeling motor neurons with $\left[{ }^{3} \mathrm{H}\right]$ leucine and $\left[{ }^{3} \mathrm{H}\right]$ lysine. The distinctness of these peaks and the total width of the slow component wave increase as the wave moves distally in the nerve. Width was measured by a line (indicated by a broken horizontal line in each profile) that intersected each wave at two-thirds of its total height. The locations of these waves were measured at the midpoints of these lines (indicated by vertical arrows). The highest points in each profile represent: $13,635 \mathrm{dpm}$ at 20 days; $8,814 \mathrm{dpm}$ at 33 days; $5,345 \mathrm{dpm}$ at 60 days; and 2,527 dpm at 85 days. 


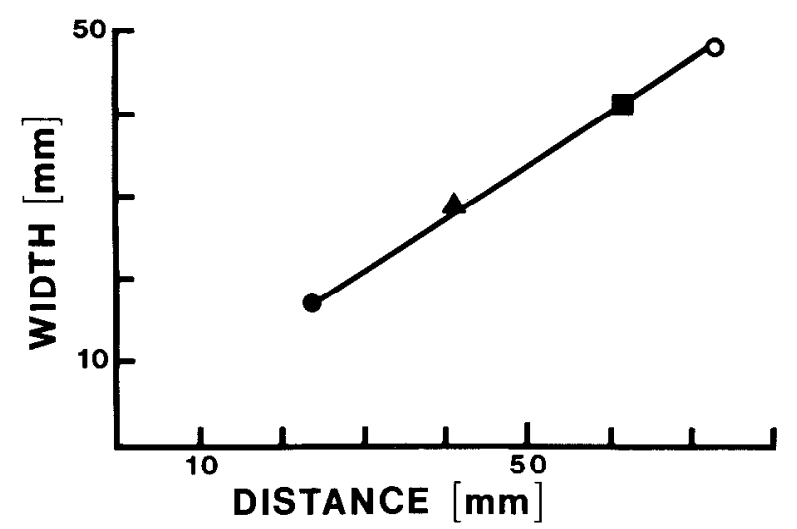

Figure 7. The width of the slow component wave in 10 -weekold animals is plotted as a function of its location at 20 (O), 33 $(\mathbf{\Delta}), 60(\mathbf{\square})$, and $85(\mathrm{O})$ days after labeling motor neurons with $\left[{ }^{3} \mathrm{H}\right]$ leucine and $\left[{ }^{3} \mathrm{H}\right]$ lysine (see the text). These data were derived from the profiles in Figure 6.

vious studies have shown that the velocity of slow axonal transport declines with age (Droz, 1965; Lasek, 1970; Hendrickson and Cowan, 1971; Komiya, 1980), but none have noted a substantial change in the rate of decline that was similar to the one we found at 10 weeks of age (Fig. 5). With regard to this change, it may be significant that these animals, which are weaned at 3 weeks of age, reach sexual maturity by 10 weeks. Other studies have demonstrated that the velocity of $\mathrm{SCb}$ also declines with age in the sensory (Komiya, 1980) and motor axons of the rat sciatic nerve (Hoffman et al., 1981). Thus, the velocity of the entire slow transport system ( $\mathrm{SCa}$ and $\mathrm{SCb}$ ) decreases with age.

This is quite different from the behavior of the fast component, which does not appear to slow down significantly in rat sciatic motor neurons until 37 to 38 weeks of age. At that time, the reduction is statistically significant but relatively small: $406 \pm 16 \mathrm{~mm} /$ day at 37 to 38 weeks of age versus $438 \pm 15 \mathrm{~mm} /$ day at 26 to 29 weeks, a $7 \%$ reduction (Stromska and Ochs, 1982). Thus, the velocity of membrane-associated proteins transported in the fast component (Forman et al., 1971) is unaltered at a time when the rate of transport of cytoskeletal proteins in the slow component changes substantially. This may, in part, be related to profound changes in the cytoskcleton that occur during postnatal development.

\section{Changes in the shape of the slow component wave during development}

We have found that the shape of the slow component wave changes during development. In animals 10 weeks old or less, it is composed of several overlapping peaks as compared to a single peak at 20 weeks. The complex shape of this wave in younger animals may reflect the distribution of labeled cytoskeletal proteins within individual axons, i.e., their distribution over relatively great distances in each axon. Alternatively, each peak could represent a separate population of motor axons in which the slow component wave moves at a distinct velocity. Although we cannot exclude the first possibility, the behavior of this wave appears to be more consistent with the latter, i.e., its width increases in direct proportion to the distance it has traveled (Fig. 7).
Our results indicate that the velocity of neurofilament transport declines during postnatal development. During this period, these motor axons are undergoing substantial growth in caliber which is directly correlated with the maturation of important electrophysiological properties such as impulse conduction velocity which increases as axons grow in caliber (Skoglund and Romero, 1965; Swallow and Griffiths, 1977; Sims and Redding, 1980). Thus, the velocity of neurofilament transport appears to be inversely correlated with the level of maturation of these axons, i.e., it is greater in less mature axons. If this is true, then we would expect the velocity of neurofilament transport to differ among axons at different stages of maturation.

During early postnatal development, the motor axons innervating proximal leg muscles in the kitten are larger in caliber and, therefore, more mature than those innervating distal muscles (Skoglund and Romero, 1965). These differences in caliber disappear as development proceeds and are not found in adult animals. If the developing rat sciatic nerve also contains several populations of motor axons which differ in their levels of maturation and the velocity of neurofilament transport is greater in less mature axons, then this could explain the presence of several overlapping peaks in the slow component wave of younger animals, i.e., 10 weeks old or less. Similarly, the presence of a single peak in 20 week-old animals could represent a stage of development when these axons have reached the same level of maturation.

\section{Role of neurofilaments in the radial growth of the axon}

Embryonic axons are thin, and their cytoskeletons consist largely, if not exclusively, of microtubules (Peters and Vaughn, 1967). Growth in axonal caliber during postnatal development is associated with a marked increase in the number of axonal neurofilaments. In fact, morphometric analyses indicate that the number of neurofilaments in myelinated axons increases in direct pro-

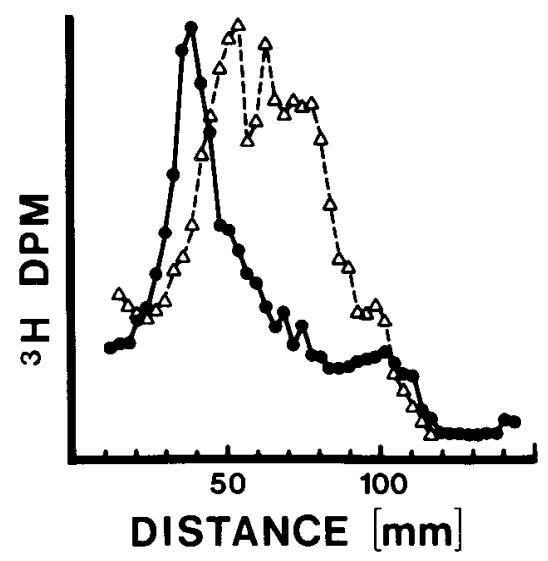

Figure 8 . The shape of the slow component wave is compared in the sciatic nerves of 10 -week $(\triangle--\triangle-\triangle)$ and 20 -week-old ( ) animals 60 days after labeling motor neurons with $\left.{ }^{3} \mathrm{H}\right]$ leucine and $\left[{ }^{3} \mathrm{H}\right]$ lysine. Mean levels of radioactivity are plotted as a function of distance from the spinal cord, with five animals in each group. The highest point in each profile represents $5345 \mathrm{dpm}$ at 10 weeks and $8145 \mathrm{dpm}$ at 20 weeks of age, respectively. 
portion to the cross-sectional area of the axon (Friede and Samorajski, 1970; Weiss and Mayr, 1971; Berthold, 1978). Thus, radial growth largely reflects the transport of neurofilaments into the axon (Hoffman et al., 1980).

Several studies indicate that the rate of radial growth declines significantly with age. For example, the crosssectional area of motor axons in the cat $\mathrm{L} 7$ ventral root increases $2^{1 / 2}$ times faster during the first 3 months of life than at later stages of development (Skoglund and Romero, 1965; Nystrom, 1968). Although we lack comparable information concerning the growth of rat sciatic motor axons, there is little doubt that the rate of radial growth declines substantially between 3 and 20 weeks of age (P. N. Hoffman, personal observations). Our results demonstrate that the neurofilament transport velocity in these axons declines at a significantly greater rate between 3 and 10 weeks of age than between 10 and 20 weeks. Assuming that these events are related, it is still not yet possible to decide whether this slowing of neurofilament transport is the cause or result of changes in the rate of radial growth. Nevertheless, since neurofilaments appear to be the principle intrinsic regulators of caliber in myelinated axons, it is likely that further studies of this relationship will provide important insights into the mechanisms of axonal growth.

\section{References}

Berthold, C. H. (1978) Morphology of normal peripheral axons. In Physiology and Pathobiology of Axons, S. G. Waxman, ed., pp. 3-63, Raven Press, New York.

Black, M. M., and R. J. Lasek (1980) Slow components of axonal transport: Two cytoskeletal networks. J. Cell Biol. 86: 616-623.

Braund, K. G., J. A. McGuire, and C. E. Lincoln (1982) Agerelated changes in peripheral nerves of the dog. II. A morphologic and morphometric study of cross-sectional nerve. Vet. Pathol. 19: 379-398.

Droz, B. (1965) Fate of newly synthesized proteins in neurons. In The Use of Radioaudiography in Investigating Protein Synthesis, C. P. Leblond and K. B. Warren, eds., pp. 159174, Academic Press, Inc., New York.

Forman, D. S., B. S. McEwen, and B. Grafstein (1971) Rapid transport of radioactivity in goldfish optic nerve following injections of labeled glucosamine. Brain Res. 28: 119-130.

Friede, R. L., and T. Samorajski (1970) Axon caliber related to neurofilaments and microtubules in sciatic nerve fibers of rats and mice. Anat. Rec. 167: 379-387.

Ha, H. (1970) Axonal bifurcation in the dorsal root ganglion of the cat: A light and electron microscopic study. J. Comp. Neurol. 140: 227-240.

Hendrickson, A. E., and W. M. Cowan (1971) Changes in the rate of axoplasmic transport during postnatal development of the rabbit's optic nerve and tract. Exp. Neurol. 30: 403422 .

Hoffman, P. N., and R. J. Lasek (1975) The slow component of axonal transport. Identification of major structural polypeptides of the axon and their generality among mammalian neurons. J. Cell Biol. 66: 351-366.

Hoffman, P. N., and R. J. Lasek (1980) Axonal transport of the cytoskeleton in regenerating motor neurons: Constancy and change. Brain Res. 202: 317-333.

Hoffman, P. N., J. W. Griffin, and D. L. Price (1980) The role of slow component $a$ (SCa) in determining axon caliber: Changes during regeneration. Soc. Neurosci. Abstr. 6: 93.

Hoffman, P. N., J. W. Griffin, and D. L. Price (1981) Changes in the axonal transport of the cytoskeleton during development, aging, and regeneration. Soc. Neurosci. Abstr. 7: 743.

Komiya, Y. (1980) Slowing with age of the rate of slow axonal flow in bifurcating axons of rat dorsal root ganglion cells. Brain Res. 183: 477-480.

Lasek, R. J. (1968) Axoplasmic transport of labeled proteins in rat ventral motoneurons. Exp. Neurol. 21: 41-51.

Lasek, R. J. (1970) Axonal transport of proteins in dorsal root ganglion cells of the growing cat: A comparison of growing and mature neurons. Brain Res. 20: 121-126.

Lasek, R. J., and P. N. Hoffman (1976) The neuronal cytoskeleton, axonal transport and axonal growth. Cold Spring Harbor Conf. Cell Prolif. 3: 1021-1049.

Laskey, R. A., and A. D. Mills (1975) Quantitative fïlm detection of ${ }^{3} \mathrm{H}$ and ${ }^{14} \mathrm{C}$ in polyacrylamide gels by fluorography. Eur. J. Biochem. 56: 335-341.

McQuarrie, I. B., S. T. Brady, and R. J. Lasek (1980) Polypeptide composition and kinetics of $\mathrm{SCa}$ and $\mathrm{SCb}$ in sciatic nerve motor axons and optic axons of the rat. Soc. Neurosci. Abstr. 6: 501.

Mori, H., Y. Komiya, and M. Kurokawa (1979) Slowly migrating axonal polypeptides. Inequalities in their rate and amount of transport between two branches of bifurcating axons. J. Cell Biol. 82: 174-184.

Morris, J. R., and R. J. Lasek (1982) Stable polymers of the axonal cytoskeleton: The axoplasmic ghost. J. Cell Biol. 92: 192-198.

Nystrom, B. (1968) Fibre diameter increase in nerves to "slowred" and "fast-white" cat muscles during postnatal development. Acta Neurol. Scand. 44: 265-294.

Peters, A., and J. E. Vaughn (1967) Microtubules and filaments in the axons and astrocytes of early postnatal rat optic nerves. J. Cell Biol. 32: 113-119.

Sims, M. H., and R. W. Redding (1980) Maturation of nerve conduction velocity and the evoked muscle potential in the dog. Am. J. Vet. Res. 41: 1247-1252.

Skoglund, S., and C. Romero (1965) Postnatal growth of spinal nerves and roots. A morphological study in the cat with physiological correlations. Acta Physiol. Scand. (Suppl. 260) 66: $1-50$.

Stromska, D. P., and S. Ochs (1982) Axoplasmic transport in aged rats. Exp. Neurol. 77: 215-224.

Swallow, J. S., and I. R. Griffiths (1977) Age related changes in the motor nerve conduction velocity in dogs. Res. Vet. Sci. 23: $29-32$.

Weiss, P. A., and R. Mayr (1971) Organelles in neuroplasmic ("axonal") flow: Neurofilaments. Proc. Natl. Acad. Sci. U. S. A. $68: 846-850$. 